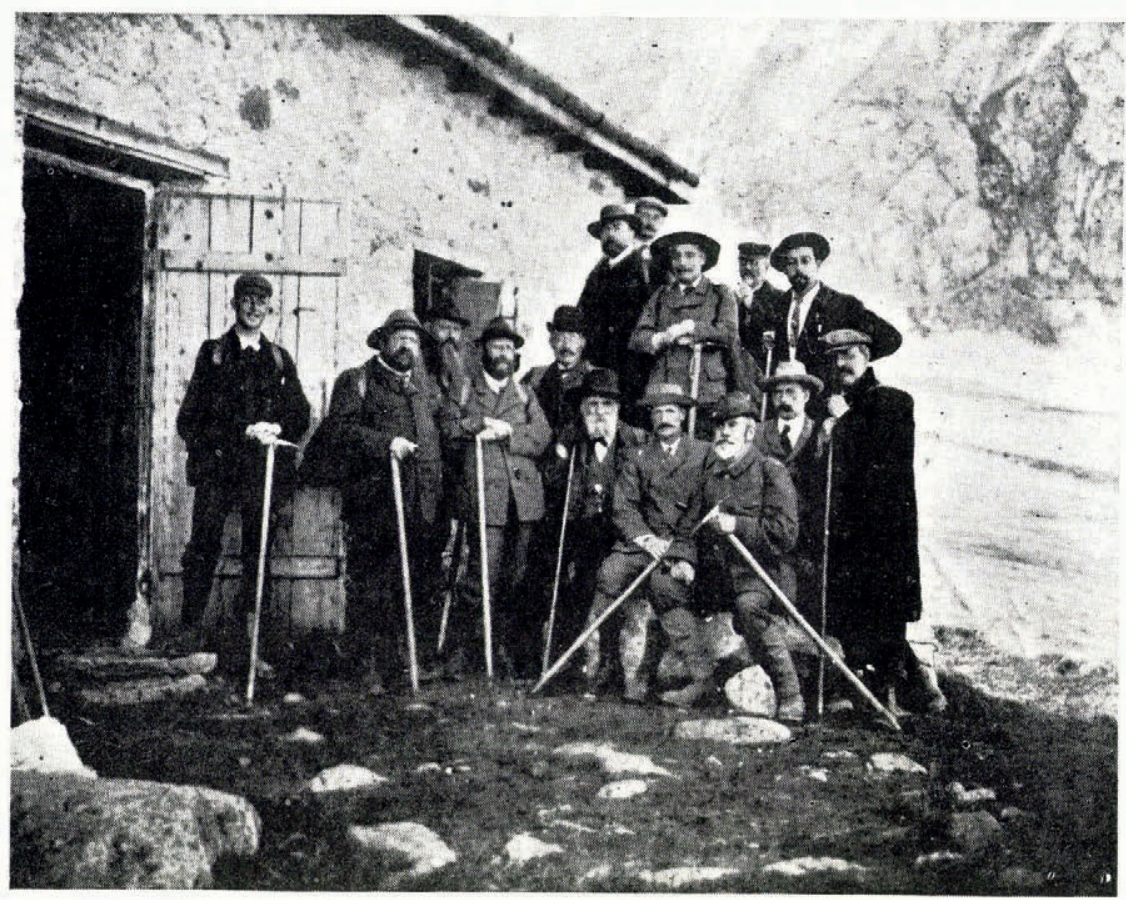

The Third International Conference on Glaciers. Left to right, back row: A. Blümcke (Nüremberg), F. Machatschek (Vienna); G. Merzbacher (Munich), K. Ұ. V. Steenstrup (Copenhagen), P. L. Mercanton (Lausanne). Front row: P. Harder (Copenhagen), E. Brückner (Halle, Saxony), H. Crammer (Salzburg), S. Finsterwalder (Munich), A. Hamberg (Stockholm), F-A. Forel (Morges), H. F. Reid (Baltimore), F. Wahnschaffe (Berlin), E. F. Garwood (London), F. Porro (Genoa)

\title{
The Third International Conference on Glaciers, 1905
}

THE photograph reproduced above was found among the papers of the late Professor E. J. Garwood and presented to the Scott Polar Research Institute. The group is standing before the Forno Hut, Maloja, on 7 September 1905.

The occasion was the third meeting of the International Conference on Glaciers. These meetings had been inaugurated by Dr. E. Richter of Graz. The first took place at Gletsch in the Valais in 1899. The second meeting, convened by Dr. Richter and Professor S. Finsterwalder of Munich, met two years later in Tirol. The third gathering took place at Maloja in 1905 under the chairmanship of Professor H. F. Reid of Baltimore, Dr. Richter having died a little while before. The main object was to investigate the banding of glaciers and it was on this occasion that Reid satisfied himself that stratification bands in the névé could persist throughout the glacier. A short paper on the findings of the group, reprinted from Les Archives des Sciences physiques et naturelles, Vol. 21, Pt. 4, 1906, p. 31 3-25, has been presented to the Society by Professor P. L. Mercanton.

There can have been few occasions in the past when so many glaciologists of high distinction had gathered together. At least three of those taking part are still living. Sebastian Finsterwalder, now eighty-eight, lives in Tirol; Paul Mercanton. is as active as ever and his many contributions to glaciology, including his annual observations on glacier fluctuation, continue to be of inestimable value to the science. Dr. F. Machatschek, the author of many important glaciological works, lives in Vienna.

One of the greatest early Swiss investigators on snow and avalanches, Forst-Inspektor J. Coaz, then eighty-three years of age, was also a member of the party but stayed below in the valley and is therefore not in the group photographed. 


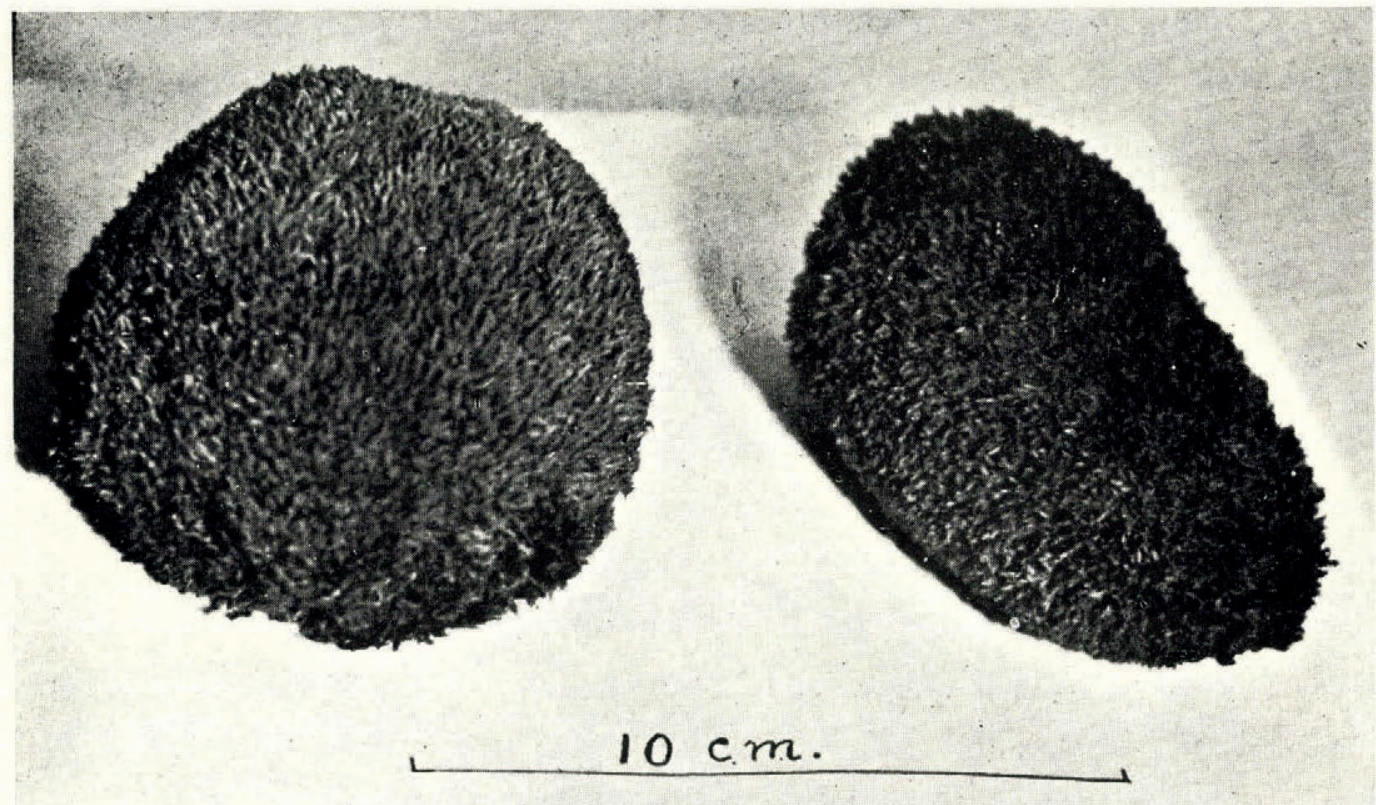

“Fökla-mýs" (see text, p. 503)
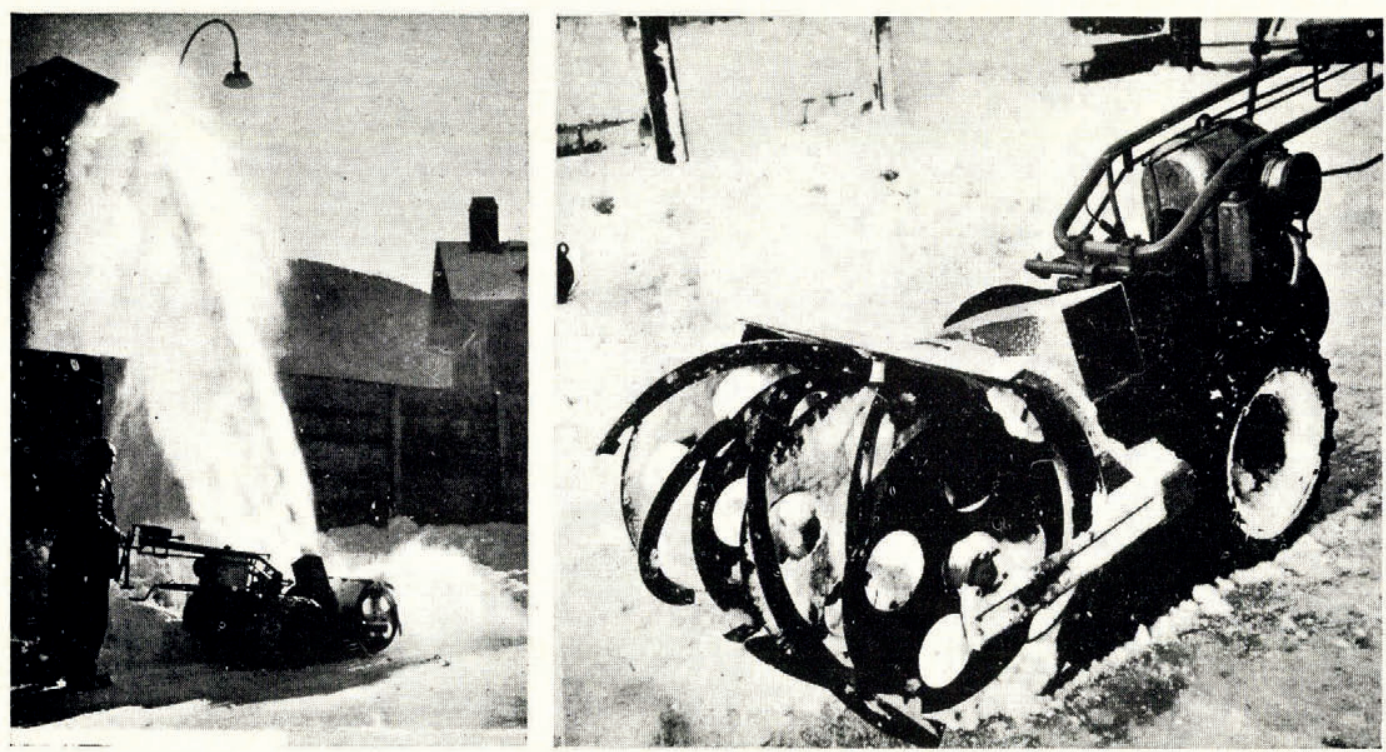

Snow plough (see text, p. 495) 